\title{
Unsecured Intracranial Aneurysms and Induced Hypertension in Cerebral Vasospasm: Is Induced Hypertension Safe?
}

\author{
Johannes Platz • Erdem Güresir • Hartmut Vatter • \\ Joachim Berkefeld • Volker Seifert • Andreas Raabe • \\ Jürgen Beck
}

Published online: 1 February 2011

(C) Springer Science+Business Media, LLC 2011 induced hypertension when compared to the natural history ( $0.5 \%$ for group $1,2.9 \%$ for group 2$)$.

Conclusion These data corroborate that induced hypertension may be a safe treatment option to prevent cerebral infarction in CVS, even in the presence of unsecured aneurysms. Our findings suggest that induced hypertension does not increase rupture of unsecured aneurysms. Given the high risk for cerebral infarction in severe CVS, we conclude that induced hypertension should not be omitted due to the presence of unsecured aneurysms.

Keywords Intracranial aneurysm .

Subarachnoid hemorrhage - Cerebral vasospasm .

Hypervolemia hypertension

\section{Introduction}

In subarachnoid hemorrhage (SAH), securing of the ruptured aneurysm is the primary goal of treatment to (1) prevent rebleeding and (2) treat cerebral vasospasm (CVS) more aggressively. CVS can be found in up to $70 \%$ of patients angiographically leading to delayed ischemic neurological deficits (DIND) in 50\% of patients with 15 to $20 \%$ dying or developing stroke [1-4].

In CVS management, the approach to augment cerebral perfusion is broadly accepted. Usually this intervention includes induced arterial hypertension, hypervolemia and hemodilution, the so called "triple-H therapy", which is also recommended for the treatment of CVS according to the guidelines by the Stroke Council of the American Heart Association (Class IIa recommendation) [5-11].

Induced hypertension appears to be the most relevant part of therapy [12]. More recently, additional invasive endovascular methods have been developed to treat 
vasospasm and are being increasingly used, e.g., percutaneous transluminal balloon angioplasty (PTA) or the intraarterial administration of vasodilating drugs [13-15].

However, arterial hypertension is generally considered a risk for aneurysm rupture although prospective studies are still lacking. [5, 11, 16-18] Recently, it was shown that a history of hypertension multiplies the risk of rupture for aneurysms smaller than $7 \mathrm{~mm}$ [19]. In normotensive patients, induced hypertension may put considerable additional stress on the aneurysm wall, thus increasing the risk of aneurysm rupture.

Still, little is known about the risk of bleeding due to induced hypertension in the presence of unsecured aneurysms; however, clinicians are often faced with patients suffering from vasospasm and harboring unsecured aneurysms [20]. This seems even more relevant when considering the results from the International Study of Unruptured Intracranial Aneurysms (ISUIA) study that showed an increased rupture rate, even for small additional aneurysms, in patients after a previous SAH from another aneurysm [21].

To date, little evidence is available assessing the risk of induced hypertension in treating CVS in the presence of unsecured aneurysms. It was therefore the aim of this retrospective study to evaluate the effects of induced hypertension after $\mathrm{SAH}$ on additional unruptured, unsecured aneurysms and ruptured unsecured aneurysms.

\section{Methods}

\section{Study Patients}

Patients presenting at our neurovascular center between January 2000 and May 2009 with non-traumatic SAH were entered in a prospectively conducted database. All patients receiving induced hypertension due to CVS with at least one unsecured aneurysm at the onset of induced hypertension were included. The patients meeting these criteria were identified and the charts reviewed.

\section{Patient Management}

After diagnosis of SAH, a four-vessel angiogram was routinely performed. Hemodynamic target values included a cerebral perfusion pressure (CPP) greater than $60 \mathrm{mmHg}$ and the correction of hypovolemia. Aneurysms were treated by clipping or coiling based on aneurysm characteristics and the clinical condition of the patient. Early aneurysm treatment (within $24 \mathrm{~h}$ ) was the goal in all patients unless the patients were hemodynamically unstable or moribund. After aneurysm obliteration, all patients were treated in the neurosurgical intensive care unit
(NICU) and received nimodipine from the day of admission either orally $(6 \times 60 \mathrm{mg} /$ day $)$ or intravenously $(2 \mathrm{mg} / \mathrm{h})$.

\section{Diagnosis of CVS}

Routine surveillance included daily transcranial Doppler (TCD) measurements. An increase in TCD flow velocity greater than $150 \mathrm{~cm} / \mathrm{s}$ was interpreted as Doppler sonographic CVS. In cases of clinical deterioration (new neurological deficit or a decrease on the Glasgow Coma Scale), a CT or MRI scan was indicated. In the absence of structural lesions or hydrocephalus, a delayed neurological deficit (DIND) due to symptomatic CVS was suspected. In some poor-grade and ventilated patients, brain tissue pO2 (pti O2) was monitored invasively ( $\mathrm{Licox}^{\circledR}$, Integra Neurosciences, Plainsboro, NJ, USA) with values below $15 \mathrm{mmHg}$ in tissue oxygenation being interpreted as CVS. Furthermore, most patients underwent CT or MRI-based perfusion studies.

In the majority of the patients, angiography was performed and the degree of angiographic vasospasm was classified into none (0-10\%), mild (11-33\%), moderate (34-66\%), and severe (67-100\%) as described by Weidauer et al. [22]. Symptomatic vasospasm was defined as (1) new DIND in the absence of other causes, (2) moderate or severe angiographic vasospasm or Doppler flow velocities $>150 \mathrm{~cm} / \mathrm{s}$ and a perfusion deficit on CT- or MRI perfusion studies or any new infarcts on neuroimaging (CT or MRI) or (3) moderate or severe angiographic vasospasm or Doppler flow velocities $>150 \mathrm{~cm} / \mathrm{s}$ and a decrease in pti $\mathrm{O}_{2}<15 \mathrm{mmHg}$ in tissue oxygen tension.

\section{Induced Hypertension}

In cases of symptomatic vasospasm, hypertension was induced with catecholamines following a stepwise protocol [12]. The treatment goal was to achieve a CPP of 80 to $120 \mathrm{mmHg}$ corresponding to mean arterial pressure (MAP) values between 90 and $130 \mathrm{mmHg}$ [23]. Other target treatment values included normovolemia in the high-normal range (central venous pressure (CVP) $>5 \mathrm{mmHg}$, hematocrit $(\mathrm{Hc}) 0.25$ to 0.40$)$. Hypervolemia was not the primary interest [12]. Systolic blood pressure (SBP, recorded from an arterial line), vital signs, and hemodynamic measurements were recorded hourly. Data were entered into a computerized database from which mean and maximum SBP, CVP, and MAP values were calculated. Fluid intake and hemoglobin values were recorded at least daily.

When conservative therapy failed patients were additionally treated endovascularly as described elsewhere $[22,24]$. 


\section{Statistical Methods}

The primary endpoint of the study was defined as the presence of rupture in any additional unruptured unsecured aneurysm or ruptured unsecured aneurysm during treatment with induced hypertension. Secondary outcome measures included any aneurysm rupture occurring later, after the treatment with induced hypertension had been finished.

Descriptive analyses were performed for all study variables. The mean and standard deviation were calculated for aneurysm diameter. To compare differences between individuals, a $t$ test was used and $P$ values calculated.

\section{Literature Review}

We performed a literature review to evaluate the impact of induced hypertension on unsecured aneurysms in other studies. The PubMed database (www.ncbi.nlm.nih.gov/ pubmed) was searched using the keywords "SAH", "triple H", "induced hypertension", "unsecured aneurysm", and "hypertensive therapy". Only literature published in English until December 2009 was included in this review. The results were screened for relevance. Copies of the original papers were retrieved and data extracted when possible. Furthermore, the references of these papers were reviewed.

\section{Results}

\section{Patient Characteristics}

Forty-five patients with symptomatic CVS after SAH and at least one unsecured aneurysm at the onset of induced hypertension were included. The mean age of patients was $49.4 \pm 10.0$ years (range: 29-79 years) and 75.6\% were women. All patients presented with SAH due to a ruptured aneurysm except for one patient who presented with $\mathrm{SAH}$ due to a ruptured dural arterial-venous fistula harboring an additional unruptured middle cerebral artery (MCA) aneurysm.

\section{Aneurysm Characteristics}

Forty-four patients had a ruptured aneurysm of which 24 were secured by clipping $(54.5 \%)$ and 16 by coiling $(36.4 \%)$. In four patients, the ruptured aneurysm remained unsecured due to the presence of severe CVS on admission or poor clinical status. In total, 78 additional unruptured unsecured aneurysms were present before aneurysm treatment in all 45 patients (Table 1; Fig. 1). In five patients (no. 17, 25, 27, 34, 38), seven additional aneurysms were clipped simultaneously when securing the ruptured aneurysm. Finally, at the onset of induced hypertension, 41 patients had 71 additional unruptured, unsecured aneurysms and four patients had four ruptured unsecured aneurysms.

The mean size of all aneurysms was $5.5 \pm 3.6 \mathrm{~mm}$ with the ruptured aneurysms being significantly larger (mean diameter $8.2 \pm 4.3 \mathrm{~mm}$, range: $1-21 \mathrm{~mm}$ ) than the unruptured ones (mean diameter $4.0 \pm 1.9 \mathrm{~mm}$, range: $1-10 \mathrm{~mm}$, $P$ value $<0.001, t$ test). The mean size of the four ruptured unsecured aneurysms was $5.3 \pm 2.2 \mathrm{~mm}$ (range: $3-8 \mathrm{~mm}$ ).

\section{Diagnosis of Vasospasm}

Cerebral vasospasm was confirmed angiographically in 37 of $45(82.2 \%)$ patients. In four patients $(8.9 \%)$, diagnosis was established on the basis of MR-imaging (including MR-angiography and MR-perfusion) alone, while in another four patients $(8.9 \%)$, the diagnosis was based on TCD and clinical worsening only.

\section{Induced Hypertension}

Mean duration of hypertensive therapy was 7.2 days (range 2-13 days) per patient and a total of 310 days for all patients. During therapy, a mean MAP of $103.01 \pm 6.52 \mathrm{mmHg}$ was achieved corresponding to a mean SBP of $160.89 \pm 11.57$ mmHg (Table 2). The maximal values were $133.60 \pm$ $13.89 \mathrm{mmHg}$ and $209.65 \pm 23.67 \mathrm{mmHg}$ for MAP and SBP, respectively. Mean CVP was $12.69 \pm 2.50 \mathrm{mmHg}$.

Thirty-five patients received norepinephrine. Of those, eight patients received a combination of norepinephrine and dobutamine and 12 patients received a combination of norepinephrine and dopamine. Two patients were administered dopamine alone, while in six patients, sufficient spontaneous hypertension was achieved. Two patients had missing hemodynamic values and therefore, were excluded from analyses that included those values.

\section{Volume Management}

On average, patients received $545 \pm 409 \mathrm{ml}$ hydroxyethylstarch (HES) 10\% per day with a mean total infusion volume of $6507 \pm 1223 \mathrm{ml}$ per day. The overall mean hemoglobin concentration $(n=45)$ during the therapy was $10.1 \pm 1.1 \mathrm{mg} / \mathrm{dl}$.

\section{Additional Invasive Treatment}

Nineteen patients $(42.2 \%)$ were treated endovascularly. In one patient, nitroprusside was applied intrathecally and eight patients underwent decompressive craniectomy due to brain edema and/or hemispheric infarctions [25, 26]. No aneurysm rupture occurred in these interventions. 
Table 1 Basic demographic characteristics, location and size of the aneurysms

\begin{tabular}{|c|c|c|c|c|c|c|c|c|c|}
\hline $\mathrm{Nr}$ & Age & Sex & $\begin{array}{l}\text { Hunt and } \\
\text { Hess grade }\end{array}$ & $\begin{array}{l}\text { Fisher } \\
\text { grade }\end{array}$ & $\begin{array}{l}\text { Location ruptured } \\
\text { aneurysm }\end{array}$ & $\begin{array}{l}\text { Size } \\
(\mathrm{mm})\end{array}$ & Operation & $\begin{array}{l}\text { Aneurysms } \\
\text { total }\end{array}$ & Localization and size (mm) \\
\hline 1 & 44 & $\mathrm{~F}$ & 4 & 3 & ICA/Pcom & 21 & Clipping & 2 & ICA paraclin. (7) \\
\hline 2 & 33 & $\mathrm{~F}$ & 2 & 3 & ICA-Bif. & 3 & Clipping & 2 & BA tip (1) \\
\hline 3 & 29 & $\mathrm{~F}$ & 3 & 4 & AcomA & 10 & Coiling & 3 & MCA (3), MCA (2) \\
\hline 4 & 53 & $\mathrm{~F}$ & 5 & 3 & MCA & 11 & Clipping & 4 & PICA (7), ICA cav (4), ICA oph (1) \\
\hline 5 & 36 & $\mathrm{~F}$ & 3 & 3 & MCA & 9 & Clipping & 2 & $\operatorname{MCA}(3) \mathrm{cl}$ \\
\hline 6 & 58 & $\mathrm{~F}$ & 3 & 3 & ICA/Pcom & 10 & Clipping & 2 & ICA oph (4) \\
\hline 7 & 36 & M & 2 & 3 & AcomA & 8 & $\mathrm{n} / \mathrm{a}$ & 4 & $\begin{array}{l}\text { M1 (3), ICA chor (3), BA (2, Coiling } \\
\text { unsuccessful) }\end{array}$ \\
\hline 8 & 41 & $\mathrm{~F}$ & 3 & 3 & ICA opht. & 5 & Coiling & 3 & ICA/P (4), ICA cav (6) \\
\hline 9 & 79 & M & 4 & 3 & AcomA & 6 & $\mathrm{n} / \mathrm{a}$ & 1 & n/a (Coiling unsuccessful) \\
\hline 10 & 46 & $\mathrm{~F}$ & 3 & 3 & PICA & 4 & Clipping & 3 & ICA clin (5), ICA oph (3) \\
\hline 11 & 49 & $\mathrm{~F}$ & 2 & 3 & Acom & 6 & Clipping & 2 & pericallosal (6) \\
\hline 12 & 57 & $\mathrm{~F}$ & 4 & 3 & Acom & 5 & Coiling & 3 & MCA (2), MCA (3) \\
\hline 13 & 59 & $\mathrm{~F}$ & 4 & 3 & MCA & 7 & Clipping & 4 & ICA oph (6), MCA (4), pericallosal (3) \\
\hline 14 & 35 & $\mathrm{~F}$ & 5 & 3 & ICA/Pcom & 10 & Coiling & 2 & Acom (2) \\
\hline 15 & 51 & $\mathrm{~F}$ & 2 & 2 & MCA & 8 & Clipping & 3 & M2 (4), ICA cav (7) \\
\hline 16 & 50 & $\mathrm{~F}$ & 2 & 3 & ICA/Pcom & 6 & Clipping & 3 & $\mathrm{ICA} / \mathrm{P}(5), \mathrm{A} 1 / 2(3)$ \\
\hline 17 & 43 & M & 2 & 3 & MCA & 8 & Clipping & 6 & $\begin{array}{l}\text { MCA (2, Clip), MCA (2, Clip), MCA (4) cl, } \\
\text { MCA (3) cl, Acom (4) }\end{array}$ \\
\hline 18 & 50 & $\mathrm{~F}$ & 4 & 3 & Acom & 6 & Coiling & 2 & $\mathrm{BA}(5)$ \\
\hline 19 & 54 & $\mathrm{~F}$ & 3 & 3 & ICA paracl & 17 & Coiling & 2 & ICA oph (4) \\
\hline 20 & 56 & $\mathrm{~F}$ & 2 & 3 & ICA/Pcom & 10 & Clipping & 3 & Acom (2), ICA/P (3) \\
\hline 21 & 46 & $\mathrm{~F}$ & 4 & 3 & ICA/Pcom & 10 & Clipping & 2 & ICA/P (5) \\
\hline 22 & 53 & M & 5 & 3 & MCA & 9 & Coiling & 2 & BA $(10)$ \\
\hline 23 & 45 & $\mathrm{~F}$ & 3 & 4 & ICA/Pcom & 10 & Coiling & 3 & Acom (4), MCA (2) \\
\hline 24 & 40 & $\mathrm{~F}$ & 2 & 4 & ICA & 18 & Clipping & 3 & ICA T (4), MCA (4) \\
\hline 25 & 43 & $\mathrm{~F}$ & 3 & 3 & MCA & 8 & Clipping & 3 & MCA (5), Acom (9, Clip) \\
\hline 26 & 47 & $\mathrm{~F}$ & 5 & 3 & MCA & 3 & Clipping & 2 & MCA (4) \\
\hline 27 & 51 & $\mathrm{~F}$ & 2 & 3 & BA/SCA & 1 & Clipping & 3 & ICA T(4, Clip), BA (1) \\
\hline 28 & 56 & M & 1 & 2 & MCA & 12 & Clipping & 2 & MCA (5) \\
\hline 29 & 42 & $\mathrm{~F}$ & 3 & 4 & Acom & 12 & Coiling & 2 & ICA oph (4) \\
\hline 30 & 38 & $\mathrm{~F}$ & 4 & 3 & MCA & 2 & Clipping & 2 & MCA (3) \\
\hline 31 & 47 & M & 3 & 4 & MCA & 4 & $\mathrm{n} / \mathrm{a}$ & 3 & MCA (4 and 5) \\
\hline 32 & 43 & $\mathrm{~F}$ & 2 & & BA & 5 & Coiling & 2 & ICA clin (6) \\
\hline 33 & 58 & $\mathrm{~F}$ & 3 & 3 & ICA/Pcom & 17 & Clipping & 2 & $\mathrm{ICA} / \mathrm{P}(5)$ \\
\hline 34 & 52 & M & 5 & 5 & ICA/Pcom & 7 & Clipping & 5 & $\begin{array}{l}\text { MCA (4, Clip), MCA (4), MCA (4) cl, } \\
\text { pericallosal (3) }\end{array}$ \\
\hline 35 & 38 & $\mathrm{~F}$ & 3 & 3 & BA & 3 & Coiling & 2 & MCA (2) \\
\hline 36 & 69 & $\mathrm{~F}$ & 3 & 3 & PICA & 7 & Coiling & 4 & MCA (5), MCA (5), MCA (2) \\
\hline 37 & 52 & $\mathrm{~F}$ & 3 & 2 & MCA & 8 & Clipping & 7 & $\begin{array}{l}\text { ICA cav (5), ACom (2), MCA (8), M1 (2), ICA } \\
\text { oph (10), ICA (3) }\end{array}$ \\
\hline $38^{\mathrm{a}}$ & 62 & $\mathrm{~F}$ & 2 & 1 & ICA-Bif. & 8 & Clipping & 4 & MCA (5, Clip), A1 (3, Clip), ICA/P (2) cl \\
\hline 39 & 65 & $\mathrm{~F}$ & 5 & 3 & Acom & 6 & Coiling & 2 & MCA (5) \\
\hline 40 & 53 & M & 4 & 3 & MCA & 12 & Clipping & 2 & BA (6) \\
\hline 41 & 60 & M & 4 & 3 & A1 & 3 & $\mathrm{n} / \mathrm{a}$ & 2 & ICA cav (3) \\
\hline 42 & 38 & M & 5 & 3 & $\mathrm{~A} 1 / \mathrm{A} 2$ & 8 & Coiling & 2 & MCA (2) \\
\hline 43 & 52 & M & 2 & 3 & dAVF & $\mathrm{n} / \mathrm{a}$ & Surgery & 1 & MCA (4) \\
\hline 44 & 53 & $\mathrm{~F}$ & 3 & 3 & Acom & 11 & Coiling & 2 & MCA (6) \\
\hline
\end{tabular}


Table 1 continued

\begin{tabular}{|c|c|c|c|c|c|c|c|c|c|}
\hline $\mathrm{Nr}$ & Age & Sex & $\begin{array}{l}\text { Hunt and } \\
\text { Hess grade }\end{array}$ & $\begin{array}{l}\text { Fisher } \\
\text { grade }\end{array}$ & $\begin{array}{l}\text { Location ruptured } \\
\text { aneurysm }\end{array}$ & $\begin{array}{l}\text { Size } \\
(\mathrm{mm})\end{array}$ & Operation & $\begin{array}{l}\text { Aneurysms } \\
\text { total }\end{array}$ & Localization and size $(\mathrm{mm})$ \\
\hline 45 & 59 & $\mathrm{~F}$ & 3 & 3 & ICA/Pcom & 8 & Coiling & 2 & MCA (3) cl \\
\hline
\end{tabular}

$\mathrm{Nr}$ patient number, $A C o m A$ anterior communicating artery, $B A$ basilar artery, bif bifurcation, $c l$ contralateral, $d A V F$ dural arterious-venousfistula, ICA internal carotid artery, MCA middle cerebral artery, PCom posterior communicating artery, PICA posterior inferior cerebellar artery, $S C A$ superior cerebellar artery, oph ophthalmic segment, chor choroidal segment, paraclin paraclinoidal segment

a Diagnosis of SAH via lumbar puncture

A

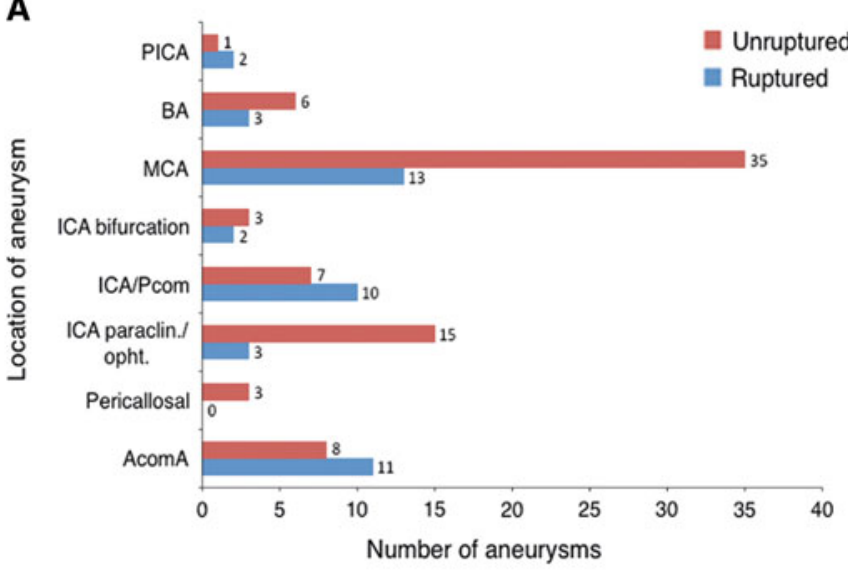

Fig. 1 Overall 122 unsecured aneurysms were identified with a majority of those being additional unruptured, unsecured (78 total) and predominantly located at the MCA (a) and the largest aneurysms (mean size) were those ruptured or secured (b). AcomA anterior

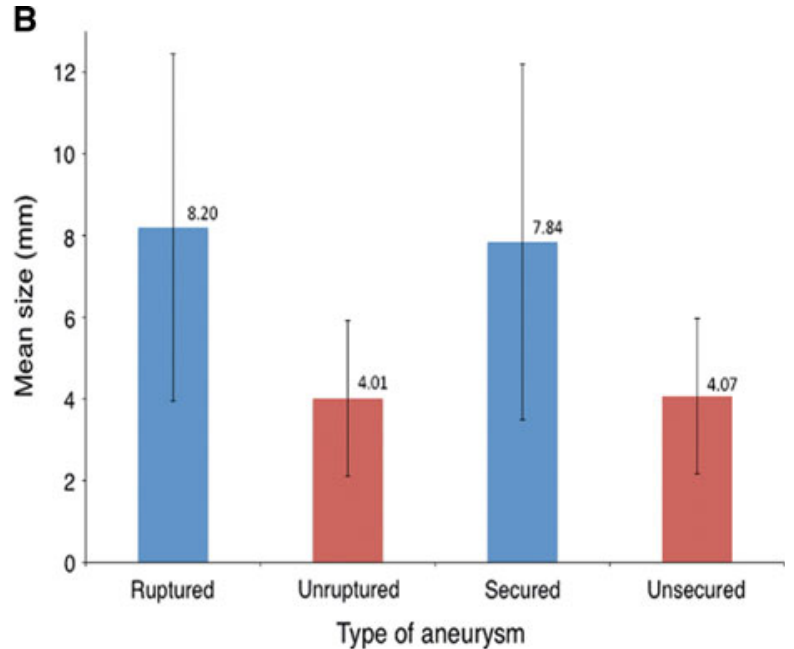

communicating artery, ICA paraclin./opht. Paraclinoid segment of the ICA located on the ophthalmic artery, ICA/Pcom ICA posterior communicating artery, PICA posterior inferior cerebellar artery

Table 2 Summary of the study participants with additional unruptured unsecured aneurysm or ruptured unsecured aneurysm

\begin{tabular}{llll}
\hline & $\begin{array}{l}\text { Group 1 (unsecured } \\
\text { unruptured aneurysms) }\end{array}$ & $\begin{array}{l}\text { Group 2 (unsecured } \\
\text { ruptured aneurysms) }\end{array}$ & Total \\
\hline Number of patients (n) & 41 & 4 & 45 \\
Number of aneurysms (n) & 71 & 4 & 122 \\
Mean aneurysm size (mm) & $4.0 \pm 1.9$ & $5.3 \pm 2.2$ & $5.52 \pm 3.6$ \\
Mean MAP achieved (mmHg) & 103.5 & 98.3 & $103.0 \pm 6.5$ \\
Max. MAP achieved (mmHg) & 134.0 & 129.8 & $133.6 \pm 13.9$ \\
Aneurysm ruptures & 0 & $0\left(2^{\mathrm{a}}\right.$ after treatment period) & 0 (during treatment) $2^{\mathrm{a}}$ (after treatment period)
\end{tabular}

${ }^{a}$ In one case, an unsecured ruptured aneurysm of the AComA ruptured 5 days after the end of induced hypertension; in the second case, the patient was on anticoagulants (mechanical heart valve) in which several rebleeds occurred but not during the period of induced hypertension and the first rebleed occurred 2 days after surgery

\section{Endpoints}

When evaluating the primary endpoint, we found that no aneurysm bled during the period of induced hypertension. However for the secondary endpoint, one patient had an unsecured ruptured aneurysm of the anterior communicating artery (AComA) ruptured 5 days after the end of induced hypertension. In another patient, who had a mechanical heart valve requiring continuous anticoagulation, the ruptured aneurysm of the left MCA rebled several times after clipping: the first rebleeding occurred 2 days after surgery due to the formation of a pseudoaneurysm 
which was then clipped again. Altogether, this patient suffered five left-sided intraparenchymal rebleedings always documented by CT. Finally, this patient died due to intractable intracranial pressure, but the unsecured contralateral MCA aneurysm never had ruptured.

\section{Patient Outcome}

Of the 45 patients, $20(44.4 \%)$ made a good recovery ( $n=12$ with $\mathrm{GOS}=5$ [good outcome], $n=8$ with GOS $=4$ [moderate disability]) while $25(55.6 \%)$ patients were dependent or had died (GOS 1-3: $n=12$ with GOS 3 [severe disability], $n=4$ with GOS $=2$ [persistent vegetative state], and $n=9$ with $\mathrm{GOS}=1 \quad$ [death], respectively, as described by the Glasgow Outcome Scale).

\section{Discussion}

In multiple intracranial aneurysms, securing of all aneurysms is not always feasible or desirable with an acceptable risk for the patient in the setting of acute SAH. Our results suggest that aggressive treatment of symptomatic CVS by induced hypertension is safe despite the presence of unsecured aneurysms (Table 2). As we considered the risk of DIND and its devastating impact on the patient's outcome greater than the risk of another aneurysm rupture, we aimed for CPP values of 80 to $120 \mathrm{mmHg}$ (MAP values between 90 and $130 \mathrm{mmHg}$ ) to treat CVS. In our series, no aneurysm ruptured during the time the treatment was applied.

In our study, as well as in other series [27], the unruptured aneurysms were significantly smaller than the ruptured ones. This presents a possible bias indicating that the risk of aneurysm rupture is related to its size [21, 27]. On the other hand, the ISUIA data demonstrated an increased risk for small aneurysms independent of their location for patients who suffered from a previous SAH by a separate aneurysm [21].

Recently, two studies showed a higher rupture risk for patients with small aneurysms if they had a history of hypertension or in the setting of multiple aneurysms [19, 28]. Up to now, few studies investigating ruptured or unruptured aneurysms have been published (Table 3). These studies tend to have different study objectives making direct comparison between results difficult. Furthermore, most studies have been limited to a small number of cases, while our study appears to be the largest series reported thus far. Other limitations of the published studies include (1) the limitation of the maximal SBP to $150,160 \mathrm{mmHg}$ or less than a $20 \%$ increase in MAP, respectively [29-31], (2) the general evaluation of the safety of triple-H therapy,

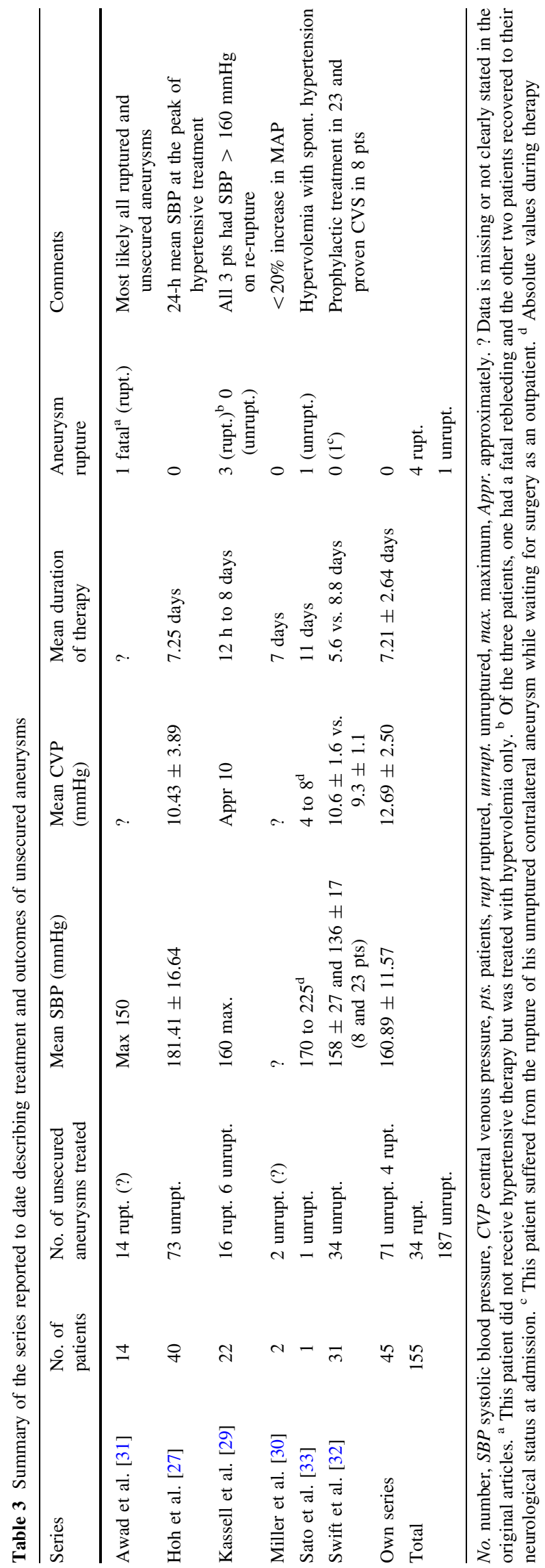


and (3) the prophylactic nature of induced hypertension with lower MAP values (mean $80.2 \mathrm{mmHg}$ ) [32].

In three of the reported series, at least one rebleeding occurred: in the series of Kassell et al. [29], three unsecured ruptured aneurysms rebled during hypertensive therapy (one being fatal, two patients recovering to their neurological status on admission). In the series of Awad et al., four out of 14 patients died due to CVS, while only one patient died because of a re-ruptured aneurysm [31], emphasizing the higher impact of DIND on the final outcome compared to treatment-related aneurysm rupture in CVS. In only one series, a patient with bilateral MCA aneurysms suffered from the rupture of an additional unsecured and previously unruptured aneurysm 11 days after SAH while receiving hypervolemic therapy [33]. Only one series is similar to ours [27]. Hoh et al. reported that no unsecured, unruptured aneurysm had ruptured due to induced hypertension in 40 patients. Unfortunately, the authors only report the maximum 24-h mean SBP and CVP, while representative mean values for the whole treatment period are missing.

Overall, including our series, there are now 121 patients with 187 additional unruptured, unsecured aneurysms reported who were treated with induced hypertension. Of these, only one aneurysm $(0.83 \%$ of patients; $0.54 \%$ of aneurysms) ruptured during therapy [33]. Remarkably, even ruptured unsecured aneurysms do not seem to rebleed more often than what is considered a natural occurrence of rebleeding (1-4\% within the first few days and 20-30\% within the first month after SAH) [11]. Including our own as well as the previously published data, the rupture rate during therapy corresponds to $11.8 \%$, rising to $17.6 \%$ if the two patients who suffered rebleeding after the treatment are included as well. This rupture rate is in line with the aforementioned natural history of these aneurysms. Thus, individual characteristics of the aneurysm may play a more important role in its risk of rupture than the short hypertensive period.

The limitations of our study were its retrospective nature and the limited number of patients. However, no larger or prospective series have been published so far. Still, the clinical relevance would warrant further prospective studies. Furthermore, we cannot answer the question if induced hypertension is a risk in the long-term rupture risk of additional aneurysms or the formation of new ones although it is unlikely that an average of only 7 days of hypertensive therapy increases that risk.

In summary, induced hypertension during the CVS does not seem to increase the risk of rupture of intracranial aneurysms after SAH. This is important for the management and clinical decision-making in this group of patients with a high risk for developing DIND.

\section{Conclusion}

The current results and the published data with more than 120 patients reported to date, advocate that treatment of CVS by induced hypertension should not be omitted because of the presence of unsecured aneurysms. This applies to additional unruptured unsecured as well as to ruptured unsecured aneurysms, however, further large prospective studies are warranted to prove this.

Acknowledgments The authors received medical editing support from Susan Wieting, Publication Office, Inselspital, Neurosurgery Department, Bern $\mathrm{CH}$ for the final preparation of this manuscript.

\section{References}

1. Heros RC, Zervas NT, Varsos V. Cerebral vasospasm after subarachnoid hemorrhage: an update. Ann Neurol. 1983;14(6): 599-608.

2. Fisher CM, Roberson GH, Ojemann RG. Cerebral vasospasm with ruptured saccular aneurysm-the clinical manifestations. Neurosurgery. 1977;1(3):245-8.

3. Haley EC Jr, Kassell NF, Torner JC. The International Cooperative Study on the Timing of Aneurysm Surgery. The North American experience. Stroke. 1992;23(2):205-14.

4. Longstreth WT Jr, Nelson LM, Koepsell TD, van Belle G. Clinical course of spontaneous subarachnoid hemorrhage: a population-based study in King County, Washington. Neurology. 1993;43(4):712-8.

5. Farhat SM, Schneider RC. Observations on the effect of systemic blood pressure on intracranial circulation in patients with cerebrovascular insufficiency. J Neurosurg. 1967;27(5):441-5.

6. Kosnik EJ, Hunt WE. Postoperative hypertension in the management of patients with intracranial arterial aneurysms. J Neurosurg. 1976;45(2):148-54.

7. Giannotta SL, McGillicuddy JE, Kindt GW. Diagnosis and treatment of postoperative cerebral vasospasm. Surg Neurol. 1977;8(4):286-90.

8. Pritz MB, Giannotta SL, Kindt GW, McGillicuddy JE, Prager RL. Treatment of patients with neurological deficits associated with cerebral vasospasm by intravascular volume expansion. Neurosurgery. 1978;3(3):364-8.

9. Sen J, Belli A, Albon H, Morgan L, Petzold A, Kitchen N. Triple$\mathrm{H}$ therapy in the management of aneurysmal subarachnoid haemorrhage. Lancet Neurol. 2003;2(10):614-21.

10. Lee KH, Lukovits T, Friedman JA. "Triple-H" therapy for cerebral vasospasm following subarachnoid hemorrhage. Neurocrit Care. 2006;4(1):68-76.

11. Bederson JB, Connolly ES Jr, Batjer HH, et al. Guidelines for the management of aneurysmal subarachnoid hemorrhage: a statement for healthcare professionals from a special writing group of the Stroke Council, American Heart Association. Stroke. 2009;40(3):994-1025.

12. Raabe A, Beck J, Keller M, Vatter H, Zimmermann M, Seifert V. Relative importance of hypertension compared with hypervolemia for increasing cerebral oxygenation in patients with cerebral vasospasm after subarachnoid hemorrhage. J Neurosurg. 2005;103(6):974-81.

13. Zwienenberg-Lee M, Hartman J, Rudisill N, Muizelaar JP. Endovascular management of cerebral vasospasm. Neurosurgery. 2006;59(5 Suppl 3):S139-47. 
14. Komotar RJ, Zacharia BE, Valhora R, Mocco J, Connolly ES Jr. Advances in vasospasm treatment and prevention. J Neurol Sci. 2007;261(1-2):134-42.

15. Beck J, Raabe A, Lanfermann H, et al. Effects of balloon angioplasty on perfusion- and diffusion-weighted magnetic resonance imaging results and outcome in patients with cerebral vasospasm. J Neurosurg. 2006;105(2):220-7.

16. de la Monte SM, Moore GW, Monk MA, Hutchins GM. Risk factors for the development and rupture of intracranial berry aneurysms. Am J Med. 1985;78(6 Pt 1):957-64.

17. Nahed BV, DiLuna ML, Morgan T, et al. Hypertension, age, and location predict rupture of small intracranial aneurysms. Neurosurgery. 2005;57(4):676-83.

18. Taylor CL, Yuan Z, Selman WR, Ratcheson RA, Rimm AA. Cerebral arterial aneurysm formation and rupture in 20, 767 elderly patients: hypertension and other risk factors. J Neurosurg. 1995;83(5):812-9.

19. Etminan N, Beseoglu K, Steiger HJ, Hanggi D. The impact of hypertension and nicotine on the size of ruptured intracranial aneurysms. J Neurol Neurosurg Psychiatry. 2010. doi:10.1136/ jnnp.2009.199661.

20. Baumann F, Khan N, Yonekawa Y. Patient and aneurysm characteristics in multiple intracranial aneurysms. Acta Neurochir Suppl. 2008;103:19-28.

21. Wiebers DO, Whisnant JP, Huston J, et al. Unruptured intracranial aneurysms: natural history, clinical outcome, and risks of surgical and endovascular treatment. Lancet. 2003;362(9378): $103-10$.

22. Weidauer S, Lanfermann H, Raabe A, Zanella F, Seifert V, Beck J. Impairment of cerebral perfusion and infarct patterns attributable to vasospasm after aneurysmal subarachnoid hemorrhage: a prospective MRI and DSA study. Stroke. 2007;38(6):1831-6.

23. Raabe A, Beck J, Berkefeld J, et al. Recommendations for the management of patients with aneurysmal subarachnoid hemorrhage. Zentralbl Neurochir. 2005;66(2):79-91.
24. Turowski B, du Mesnil de Rochemont R, Beck J, Berkefeld J, Zanella FE. Assessment of changes in cerebral circulation time due to vasospasm in a specific arterial territory: effect of angioplasty. Neuroradiology. 2005;47(2):134-43.

25. Guresir E, Raabe A, Setzer M, et al. Decompressive hemicraniectomy in subarachnoid haemorrhage: the influence of infarction, haemorrhage and brain swelling. J Neurol Neurosurg Psychiatry. 2009;80(7):799-801.

26. Guresir E, Schuss P, Vatter H, Raabe A, Seifert V, Beck J. Decompressive craniectomy in subarachnoid hemorrhage. Neurosurg Focus. 2009;26(6):E4.

27. Hoh BL, Carter BS, Ogilvy CS. Risk of hemorrhage from unsecured, unruptured aneurysms during and after hypertensive hypervolemic therapy. Neurosurgery. 2002;50(6):1207-11.

28. Sonobe M, Yamazaki T, Yonekura M, Kikuchi H. Small unruptured intracranial aneurysm verification study: SUAVe study, Japan. Stroke. 2010;41:1969-77.

29. Kassell NF, Peerless SJ, Durward QJ, Beck DW, Drake CG, Adams HP. Treatment of ischemic deficits from vasospasm with intravascular volume expansion and induced arterial hypertension. Neurosurgery. 1982;11(3):337-43.

30. Miller JA, Dacey RG Jr, Diringer MN. Safety of hypertensive hypervolemic therapy with phenylephrine in the treatment of delayed ischemic deficits after subarachnoid hemorrhage. Stroke. 1995;26(12):2260-6.

31. Awad IA, Carter LP, Spetzler RF, Medina M, Williams FC Jr. Clinical vasospasm after subarachnoid hemorrhage: response to hypervolemic hemodilution and arterial hypertension. Stroke. 1987;18(2):365-72.

32. Swift DM, Solomon RA. Unruptured aneurysms and postoperative volume expansion. J Neurosurg. 1992;77(6):908-10.

33. Sato Y, Kakino S, Ogasawara K, Kubo Y, Kuroda H, Ogawa A. Rupture of a concomitant unruptured cerebral aneurysm within 2 weeks of surgical repair of a ruptured cerebral aneurysm-case report. Neurol Med Chir (Tokyo). 2008;48(11):512-4. 